\title{
The Construction of the Modules Composing the CMS Superconducting Coil
}

\author{
P. Fabbricatore, D. Campi, C. D’Urzo, S. Farinon, A. Gaddi, M. Greco, B. Levesy, L. Loche, R. Musenich, \\ F. Rondeaux, and R. Penco
}

\begin{abstract}
CMS (Compact Muon Solenoid) is a general-purpose detector designed to run at the highest luminosity at the CERN Large Hadron Collider (LHC). Its distinctive features include a 4 T superconducting solenoid with a $6 \mathrm{~m}$ diameter by $12.5 \mathrm{~m}$ long free bore, enclosed inside a 10,000-ton return yoke. The construction of the five modules composing the coil is presently under way. The methods for constructing large aluminum alloy mandrels, for winding the reinforced conductor with high accuracy of the winding pack and for impregnating the single large modules $(50 \mathrm{t})$ have been assessed through the construction of a module prototype. The prototype has the same radius as a CMS module $(6900 \mathrm{~mm}$ outer diameter), but a shorter axial length $(670 \mathrm{~mm}$ against 2500 for the module). The relevant technological result was the understanding of the methods for obtaining a large coil with a very limited shape deformation $( \pm 2.5 \mathrm{~mm}$ on diameter $)$ for allowing the precise mounting of the modules. This paper describes the main technical issues of the prototype and of the construction of the first modules, the geometrical and RT tests performed on them and the common problems related to the series construction of large superconducting coils.
\end{abstract}

Index Terms-Al stabilized conductors, detector magnets, LHC project, winding.

\section{INTRODUCTION}

$\mathbf{T}$ HE CMS experiment (Compact Muon Solenoid) is a general-purpose, proton-proton detector designed to run at the highest luminosity of the LHC [1]. Distinctive features of the CMS detector include a high-magnetic-field solenoid (4 T) coupled with a multilayer muon system, a fully active scintillatingcrystal electromagnetic calorimeter, a tile hadronic calorimeter, and a powerful inner tracking system. The magnetic length is $12.5 \mathrm{~m}$ and the free bore is $6 \mathrm{~m}$ diameter [2]. The coil is composed of 5 modules each $2.5 \mathrm{~m}$ long and weighing $50 \mathrm{t}$. Modules are manufactured by the inner winding technique; 4 layers of reinforced conductor are wound inside an Al-alloy mandrel. A conductor length of $2.5 \mathrm{~km}$ is required for each layer. This conductor is a particular feature of the CMS winding; as reported in previous papers [3], [4], it is made of a Rutherford cable co-extruded with pure aluminum and mechanically reinforced with aluminum alloy, applied through an EB-welding process. The coil design takes into account that the winding is able to withstand considerable hoop stress (130 MPa) with the external me-

Manuscript received October 21, 2003.

P. Fabbricatore, S. Farinon, M. Greco, and R. Musenich are with INFN-Genova, 16146 Genova, Italy (e-mail: pasquale.fabbricatore@ge.infn.it). D. Campi and A. Gaddi are with CERN-Geneva, Switzerland.

C. D'Urzo, L. Loche, and R. Penco are with Ansaldo Superconduttori, 16152 Genova, Italy.

B. Levesy and F. Rondeaux are with CEA-Saclay, France.

Digital Object Identifier 10.1109/TASC.2004.829717 chanical structure playing only a minor role. The hoop and axial magnetic strength developed in the conductor are counteracted by the reinforcement in the conductor itself. This approach allows limiting the shear stress level inside the winding; namely at the border winding-external mandrel [5].

Nevertheless the construction of a winding using a reinforced conductor requires technological developments for both the conductor and the winding. Several problems related to the winding were faced and solved through a long preparatory activity and finally assessed with the construction of a module prototype. The paper deals with the main topics related to the prototype construction, especially with the methods for obtaining a good geometrical circularity. The modules construction is also discussed, stressing the differences with respect to the prototype and the aspects related to a large coils series construction.

\section{Module Construction Developments}

The construction of the CMS modules presented several technological problems, among them the most remarkable were:

- Mandrel construction. Though the winding is mechanically self-supporting, an external mandrel is required for several reasons (support during winding operations, attaching the supporting system, quench back, cool-down). This mandrel, made of high strength aluminum alloy (5083-H321), is only $50 \mathrm{~mm}$ thick (on a $7 \mathrm{~m}$ diameter) and poses severe construction problems regarding the cylindricity requirements, as discussed in [6].

- Winding method. The CMS conductor is so stiff (the momentum of inertia is as high as $4.7210^{-7} \mathrm{~m}^{4}$ ) that the usual inner winding technology (used for several existing detector coils) cannot be applied. A momentum of $4400 \mathrm{Nm}$ is required to bend the conductor at a radius of about $2 \mathrm{~m}$, which is necessary for having a final radius around $3 \mathrm{~m}$ (as a result of the spring-back effect). In order to have an acceptable winding quality, the first strong requirement is related to the bending device, which must be able to impose a constant radius within $10 \mathrm{~mm}$. Once each turn is led to approach the winding (internally against the mandrel or the former layer), it is necessary to push it longitudinally and radially. Secondly, while the classical pure Al-stabilized conductors are so soft that only a small force is required, for a stiff conductor a higher force must be applied with the risk of damaging the insulation. A winding line able to handle the reinforced conductor was developed [7]. Here it is reminded that the 
bending unit includes a two-step bending process, while the positioning of the conductor in the winding pack is based on a special three-hands machine, that clamps the conductor and pushes it.

- Impregnation. In principle, the epoxy impregnation under vacuum is not different from that used for other existing large coils. Nevertheless, the amount of resin for each module (1000 l) is quite large and coupled with a high weight of the module, poses significant technological challenge.

- Module to module mechanical mounting. The crucial point is to obtain modules with a limited radius variation (a maximum difference of $5 \mathrm{~mm}$ is allowed between maximum and minimum diameter). For larger spreads, the mounting may be hindered due to the lack of fitting between the end flanges.

- A preparatory activity was carried out for better defining the envisaged construction techniques. Then the construction of a module prototype was undertaken. The prototype module has the same radius of a CMS module $(6900 \mathrm{~mm}$ outer diameter), but a shorter axial length (670 $\mathrm{mm}$ against $2500 \mathrm{~mm}$ for the module). After the prototype construction, the module construction started at Ansaldo Superconduttori.

\section{PROTOTYPE CONSTRUCTION}

\section{A. Basic Principles and Scopes}

As discussed in the introduction, one of the central points of the CMS coil construction is the capability to mechanically fit two $50 \mathrm{t}$ coils ( $7 \mathrm{~m}$ diameter). The coupling is made by a series of M24 Titanium bolts and pins, fixed at the end flanges of each module. The allowed misalignment between the threaded holes of the coupling modules is $2.5 \mathrm{~mm}$. This results in a tolerance on the module circularity of $5 \mathrm{~mm}$ (this tolerance also comes from requirements on coil-cryostat integration). The starting point of the module construction is the external mandrel, which gives the support for the inner winding. If the coil has to be round inside the required tolerances, it is mandatory that the mandrel is constructed within tighter tolerances (cylindricity less than 1 $\mathrm{mm})$. However, the mandrel is obtained through a process [6] passing from the bending and the welding of Al-plates to the welding of Al-alloy seamless flanges, to mechanical machining and finishing with the welding of the cooling circuits. At no stage the mandrel can be thermally treated for releasing the mechanical stresses caused by the construction process (especially the welding operations), otherwise the yield strength would be lowered under the requirement (209 MPa at 4.2 K). If mechanical stresses are not released, the mandrel is not mechanically stable and the requirement on the circularity cannot be fulfilled.

In order to overcome this problem and to keep under control the mandrel diameter during the construction, two stiffening structures are involved: an inner large ring is used during welding and outer machining operations, while an outer ring is used when the inner wall is machined. Only at the end of the construction, the mandrel is let free from constraining mechanical structures (Fig. 1 shows the finished prototype mandrel), just to check the mandrel deformation (which ranges around $20 \mathrm{~mm}$ of

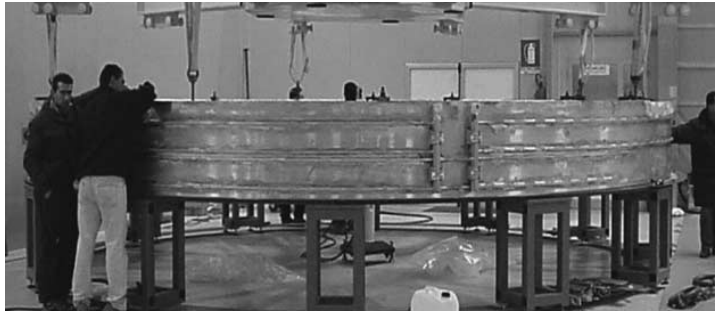

Fig. 1. The prototype mandrel.

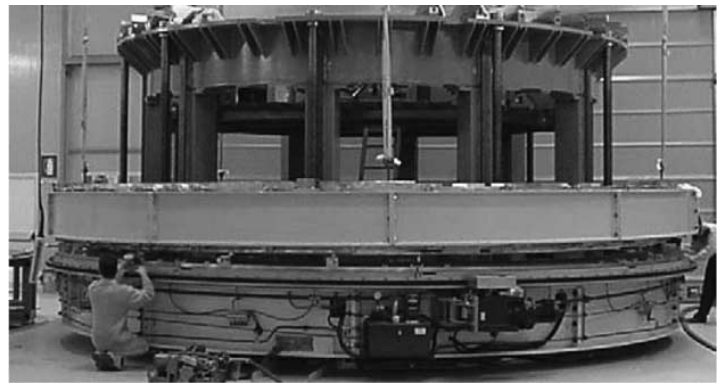

Fig. 2. The prototype mandrel with the outer reinforced ring is mounted onto the winding table.

difference between maximum and minimum diameters). Then an outer mechanical structure is applied for keeping the mandrel round again (to within $1 \mathrm{~mm}$ ) during the winding, as shown in Fig. 2, where the mandrel with stiffening ring is mounted on the winding table.

The CMS conductor is so stiff that it determines the final circularity of the module, so obtain a round coil, the winding itself must be as round as possible. In order to get this result, two conditions shall be fulfilled:

1) the mandrel circularity shall be excellent;

2) the conductor shall be bent on a constant radius and perfectly coupled to the mandrel.

In this case, once the coil has been wound, the external stiffening and rounding tool can be safely removed, because, at this stage, the deformation of the mandrel is limited by the winding stiffness. This idea was checked through the construction of the prototype, which also served for testing the complete construction process and for training the operators.

\section{B. Construction Details}

The prototype was wound using two prototype conductor lengths for a total of $2.5 \mathrm{~km}$. Though these lengths were not yet completely optimized, the winding did not meet any particular difficulty.

Fig. 3 shows some pictures of the prototype during winding, emphasizing the role of the bending unit and of the "threehands" device for the conductor positioning inside the winding pack. After winding, the prototype was prepared for the impregnation under vacuum by coupling the coil with a mechanical structure able to axially compact the winding at $1.5 \mathrm{MPa}$ (Fig. 4). Furthermore, the coil was completely enclosed in an aluminum envelope acting as a resin vessel. The impregnation (Fig. 5) was performed inside a large dedicated vacuum chamber constructed on site (being not transportable due to the huge dimensions). The thermal heating, able to heat the coil up to 

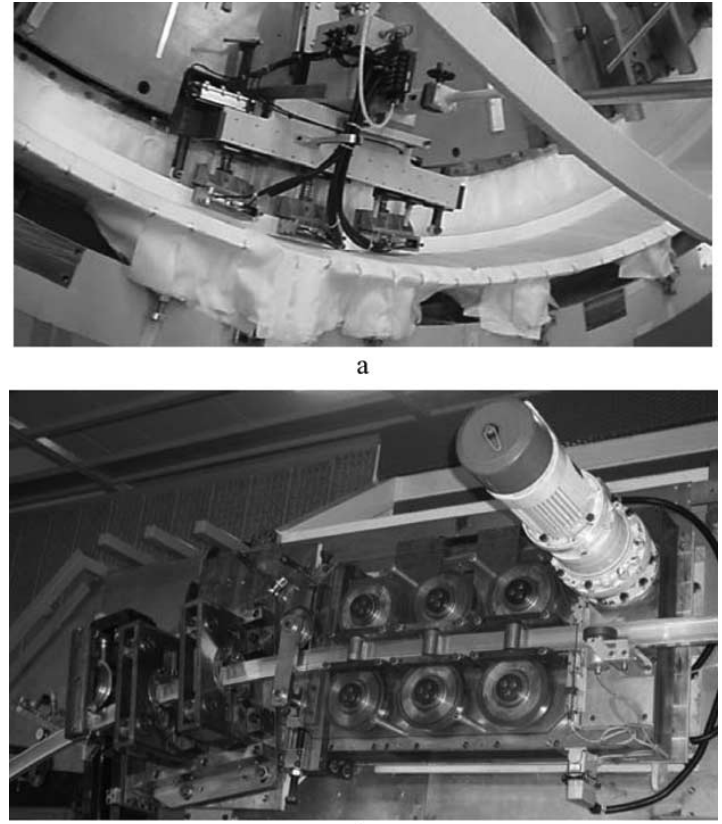

Fig. 3. The prototype during the winding operation. In a) one can see the final positioning system, whilst, b) shows the bending unit.

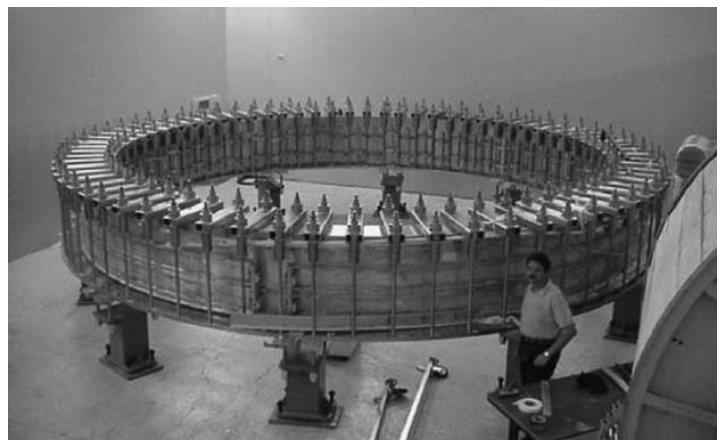

Fig. 4. The prototype, coil after winding, ready for impregnation and equipped with clamps.

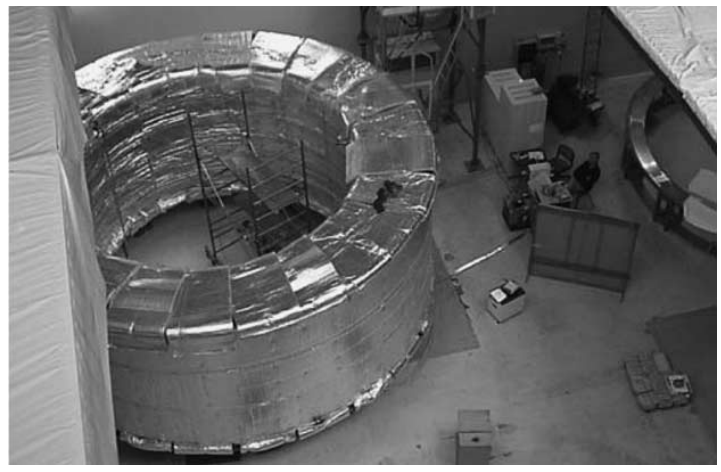

Fig. 5. Top view of the vacuum vessel during prototype impregnation.

$135^{\circ} \mathrm{C}$, was carried out by feeding current to the coil (up to 500 A) coupled in an anti-inductive layout to avoid problems with fringe field. Fig. 6 shows the prototype as extracted from the impregnation mold.

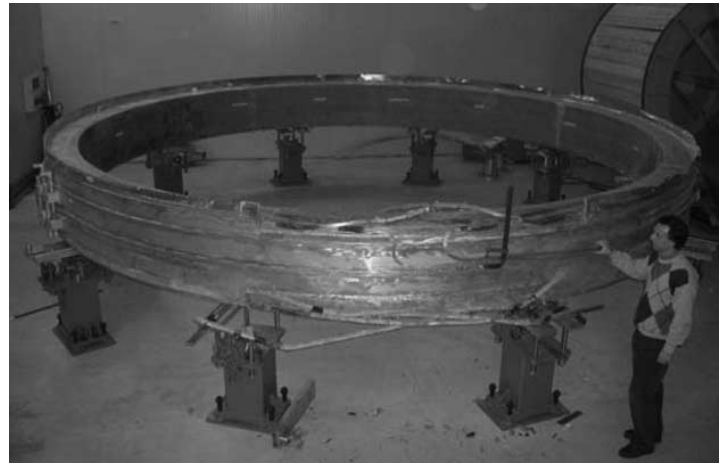

Fig. 6. The prototype coil as extracted from the mold after impregnation.

\section{Results}

After impregnation, the dimensions of the prototype were carefully checked. We found that the circularity of the coil was $\pm 2.5 \mathrm{~mm}$; i.e., the maximum difference between minimum and maximum diameter was within $5 \mathrm{~mm}$. This result confirmed the correctness of our approach and opened the way to the modules construction.

Another good result came from the measurement of the coil height, ranging from 650.1 to $650.7 \mathrm{~mm}$. This result was obtained by virtue of both the conductor dimension constancy and the compressive capability of the turn-to-turn insulation. This is a special textured glass able to compact as much as $25 \%$ under a pressure of 1.2 $\mathrm{MPa}$. As the insulation is $1.2 \mathrm{~mm}$ thick, we have the possibility to control the height of the winding within $8 \mathrm{~mm}$ (for the prototype having 27 turns per layer, while for the real modules we can control the height up to $32 \mathrm{~mm}$ ).

The electrical ground insulation was also checked by applying $2 \mathrm{kV}$ DC between each layer and the mandrel and detecting the leakage currents, found in the range 1-2 $\mu \mathrm{A}$.

\section{Modules CONSTRUCTION}

The construction of the five modules composing the CMS coil started in March 2002 with the first welding activities on the mandrel for the first module, named CB-2. The modules are constructed according to the mounting sequence from $\mathrm{CB}-2$ to $\mathrm{CB}+2$. In general the construction phases (Mandrel construction, Winding, Impregnation, Cleaning and Exits preparation) have confirmed the experience acquired with the prototype construction. Nevertheless, some modifications were implemented to the tools and to the procedures due to the large dimensions and, mainly, to the weight of the modules (50 t).

A very challenging activity is constituted by the impregnation under vacuum requiring 10001 of resin for filling each module (including technical spaces around the electrical exits) plus 2001 for filling the resin vessel well above the $2.5 \mathrm{~m}$ coil height. It takes 7 days to warm up the coil to the impregnation temperature $\left(80^{\circ} \mathrm{C}\right)$ and 5 days then to reach the curing temperature $\left(135^{\circ} \mathrm{C}\right)$. The cool-down at room temperature takes about 10 days. The real impregnation time (for filling the vessel containing the coil) is 4 days. No more time is allowed in order not to start the natural resin gelling before the coil is completely impregnated.

Figs. 7, 8, and 9 show some phases of CB-2 construction from winding to extraction from the impregnation mold. At present 


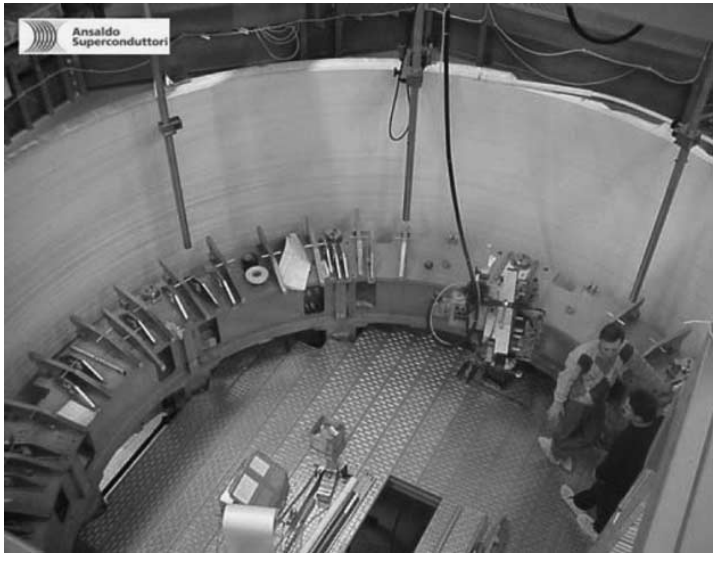

Fig. 7. CB-2 module during the winding.

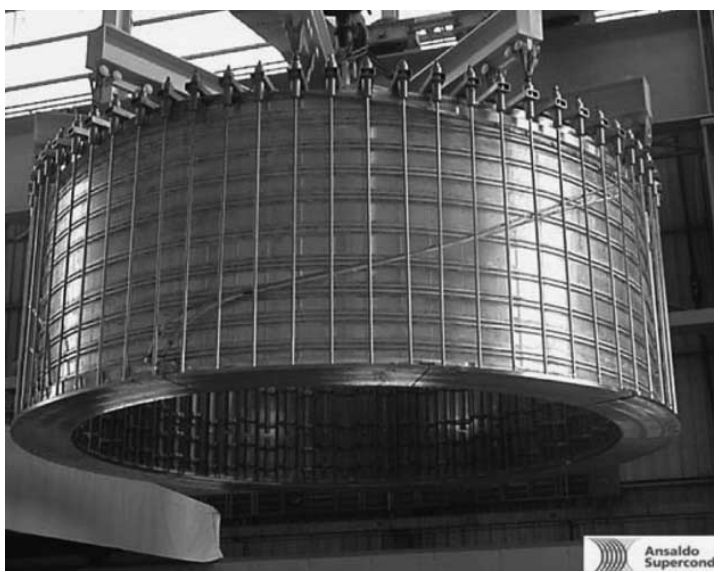

Fig. 8. CB-2 module ready for vacuum impregnation under vacuum. The coil is axially pressed at $1.2 \mathrm{MPa}$ using 140 stainless steal tie-rods. Belleville washers are placed on both upper and lower flanges in order to keep the axial load in any stage of the impregnation process.

time two modules (CB-2 and CB-1) have been finished, one module $(\mathrm{CB} 0)$ is in winding while the mandrels of the remaining modules $(\mathrm{CB}+1$ and $\mathrm{CB}+2)$ are in advanced construction phase.

\section{CONCLUSION}

The construction of a short prototype has validated the fabrication concepts for the CMS coil. Though some changes in the tooling were necessary, the construction of the five huge com-

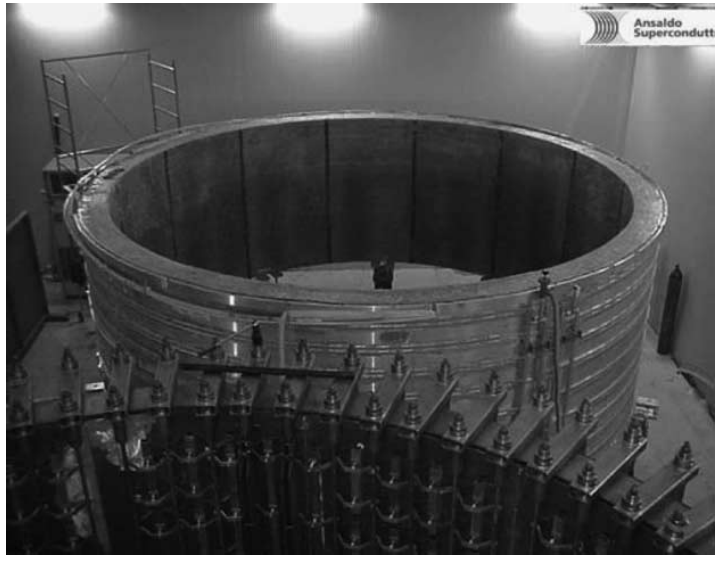

Fig. 9. CB-2 after impregnation (back). CB-1 in preparation for impregnation (front).

ponent modules is under way with the target to finish these activities within first half of 2004 .

\section{REFERENCES}

[1] A. Hervé, B. Blau, D. Campi, P. Cannarsa, B. Curè, P. Fabbricatore, S. Farinon, F. Feyzi, A. Gaddi, H. Gerwig, M. Greco, J. P. Grillet, V. Kaftanov, F. Kircher, V. Klyukin, B. Levesy, R. Loveless, G. Maire, R. Musenich, Y. Pabot, A. Payn, G. Perinic, P. Petiot, F. Rondeaux, H. Rykaczewski, E. Sbrissa, S. Sequeira Tavares, S. Sgobba, R. P. Smith, L. Veillet, and G. Waurick, Status of the Construction of CMS Magnet, , this conference.

[2] A. Hervé, "The CMS detector magnet," IEEE Trans. Appl. Supercond., vol. 10, no. 1, pp. 389-394, March 2000.

[3] I. L. Horvath, B. Dardel, H. P. Marti, J. Neuenschwander, R. P. Smith, P. Fabbricatore, R. Musenich, A. Calvo, D. Campi, B. Curè, A. Desirelli, G. Favre, P. L. Riboni, S. Sgobba, T. Tardy, and S. Sequeira Lopes Tavares, "The CMS conductor," IEEE Trans. Appl. Supercond., vol. 10, no. 1, pp. 395-398, March 2000.

[4] B. Blau, D. Campi, B. Curè, R. Folch, A. Hervè, I. L. Horvath, F. Kircher, R. Musenich, J. Neuenschwander, P. L. Riboni, B. Seeber, S. Tavares, S. Sgobba, and R. P. Smith, "The CMS conductor," IEEE Trans. Appl. Supercond., vol. 12, no. 1, pp. 345-348, March 2002.

[5] "The Magnet Project: Technical Design Report," CERN: CMS Magnet Collaboration, vol. CERN/LHCC97-10, CMS TDR 1, 1997.

[6] S. Sgobba, C. D’Urzo, P. Fabbricatore, and S. Sequeira Tavares, Mechanical Prerformance at Cryogenic Temperature of the Modules of the External Cylinder of CMS and Quality Controls Applied During Their Fabrication, , this conference.

[7] P. Fabbricatore, D. Campi, C. D'Urzo, S. Farinon, A. Gaddi, B. Levesy, L. Loche, R. Musenich, F. Rondeaux, R. Penco, and N. Valle, "The winding line for the CMS reinforced conductor," IEEE Trans. Appl. Supercond., vol. 12, no. 1, pp. 358-361, March 2002. 